\title{
Roles and the compositional semantics of role-denoting relational adjectives ${ }^{1}$ Curt ANDERSON - Heinrich-Heine-Universität Düsseldorf, SFB 991 \\ Sebastian LÖBNER — Heinrich-Heine-Universität Diusseldorf, SFB 991
}

\begin{abstract}
The semantics of adjectives related to nominals denoting societal roles, such as presidential (from president), have remained understudied. We examine the semantics of what we call role-denoting relational adjectives, providing a formal analysis using the notion of a frame, a unified representation for lexical knowledge, world knowledge, and context. The frames we propose are based on a constructivist philosophical understanding of social roles, leading us to posit a multi-tiered ontology of events and individuals. Using frames and our ontology, we provide a general semantics for role-denoting relational adjectives and roles.
\end{abstract}

Keywords: modification, adjectives, relational adjectives, events, non-intersective adjectives, roles, natural language metaphysics, frame semantics.

\section{Introduction}

\subsection{Presidential affairs}

Some role nominals such as president show an ambiguity between readings related to an official role and to readings related to the person inhabiting the role. In (1), the natural interpretation for the sentence is that the president as a private person visited his mother; no inference arises that this was part of the official duties of being president. However, in (2), that inference is possible. The natural interpretation is that this was an official visit as part of the duties of the office. Correspondingly, president in (1) refers to simply the person inhabiting the office, while in (2) the same nominal has a preference to refer to the person qua officeholder, the person inhabiting the role.

That these predications involve meanings of a particular sort (e.g., inferences regarding whether events are related to particular official responsibilities or not) can be demonstrated with certain modifiers such as private (for personal acts) and as head of state (for official acts), which serve to single out certain interpretations of these sentences.

The president visited his mother.

(personal visit preferred)

(2) The president visited the Canadian prime minister.

(official visit preferred)

The different readings of these sentences are driven in large part by our understanding of social roles in the world. Heads of state (like Canadian prime minister Justin Trudeau) are visited in the course of carrying out the official duties and responsibilities of an office. On the other hand, one's family are (typically) not in a social role that would make them eligible for being visited

\footnotetext{
${ }^{1}$ We thank Henk Zeevat, Willi Geuder, Wiebke Petersen, Gottfried Vosgerau, Gerhard Schurz, Markus Schrenk, Katja Gabrovska, Ai Taniguchi, and audiences at Sinn und Bedeutung 22, TbiLLC 2017, Heinrich-Heine-Universität Düsseldorf, and Carleton University for their comments and discussion. This work was supported by DFG SFB 991 "The Structure of Representations in Language, Cognition, and Science," project C10. All errors are our own.
} 
in an official capacity. Thus, our understanding of the relationship between the responsibilities and duties of offices, of heads of state (and other state-level actors) and private persons bears directly on our conceptualization of the semantics of role terms.

English allows for ways of converting nouns to adjectives, such as with the -al suffix. When these role nominals arise as adjectives (i.e., president to presidential), however, a puzzle arises with attributions similar to the ones in (1) and (2). If we assume, as we will below, that the use of the adjective within an NP implicitly relates to a potential referent of the root noun, we observe that the adjective can relate (in this sense) only to the office, not to the incumbent, unlike the root noun itself. The pattern is demonstrated in (3), where the deverbal noun visit, when modified by presidential, allows only for a reading related to official action by a president; conversely, the sentence in (4) does not entail that the visit was an official visit.

$$
\text { a presidential visit }\left\{\begin{array}{l}
\# \text { to the president's mother } \\
\text { to the Canadian prime minister }
\end{array}\right\}
$$

(4) The president visited his mother.

No ENTAILMENT: There was a presidential visit to the president's mother.

A distinction in the readings available manifests with adjectival modifiers versus Saxon genitives as well. Saxon genitives allow for a reading where the possessed object is interpreted as relating to the possessor as a person. However, the adjective only allows for an interpretation where the possessed object must relate to the possessor in the context of the role they inhabit. For instance, the presidential desk is the particular desk the president uses in their official duties, while the president's desk could refer both to the presidential desk, but also to a desk they may happen to use as a private person (such as a personal desk used in a home study). Similarly, while the presidential advisor is the advisor to the president for matters relating to the office of president, the president's advisor can also refer to an advisor who advises the president in a non-official way (such as a tax advisor).

a. the president's desk

b. the presidential desk

(6) a. the president's advisor

b. the presidential advisor (personal reading possible) (role reading only)

(personal reading possible) (role reading only)

Parallel observations apply to NN compounds: formations such as president advisor and president office, if acceptable, although unusual, ${ }^{2}$ would only have the office reading. There is a simple explanation for the parallel observations concerning the $\mathrm{A}+\mathrm{N}$ construction and compounds: neither the adjective nor the modifier of the compound refers to what the adjective's root noun and the first part of the NN compound would refer to when in referential use. In both cases, only the modified noun refers. In both constructions, the referent of the referring noun is

\footnotetext{
${ }^{2}$ German would have compounds with the first noun Präsident instead of A+N constructions with the adjective derived from Präsident: Präsidentenberater ("presidential advisor"), Präsidenteneskorte ("presidential motorcade"), Präsidentenbesuch ("presidential visit"), Präsidentenamt ("presidential office”), and so on.
} 


\begin{tabular}{|c|c|c|}
\hline $\mathrm{N} \rightarrow \mathrm{A}$ & $\begin{array}{l}\text { president-presidential } \\
\text { Canada-Canadian }\end{array}$ & parent-parental \\
\hline $\mathrm{A} \rightarrow \mathrm{N}$ & $\begin{array}{l}\text { electricity - electric } \\
\text { semantics - semantic } \\
\text { civilian - civil }\end{array}$ & $\begin{array}{l}\text { municipality - municipal } \\
\text { electronics - electronic }\end{array}$ \\
\hline $\mathrm{A}=\mathrm{N}$ & $\begin{array}{l}\text { military - military } \\
\text { public - public }\end{array}$ & official-official \\
\hline $\mathrm{A}, \mathrm{N}$ & $\begin{array}{l}\text { pope - papal } \\
\text { mother - maternal } \\
\text { mind - mental }\end{array}$ & $\begin{array}{l}\text { lungs - pulmonary } \\
\text { king/queen/prince/princess - royal } \\
\text { body - physical }\end{array}$ \\
\hline
\end{tabular}

Table 1: Pairs of adjectives and co-nouns / nouns and co-adjectives

related to what would be the referent of the root or modifier noun. Being related to does not amount to reference, though. There can be a presidential desk without there being a president, or presidential advisors without a president to advise.

\subsection{Co-nominal adjectives}

In this paper, we focus on role-denoting relational adjectives. These form a subclass of adjectives that are in a morphological relationship to nouns and/or in a particular semantic relationship to them. In the prototypical cases, there is a noun and a morphologically derived adjective; sometimes, $\mathrm{N}$ and $\mathrm{A}$ are of the same form; sometimes the direction of derivation is from $\mathrm{A}$ to $\mathrm{N}$; and sometimes there is no synchronic morphological relationship at all. We will refer to adjectives of this type as "co-nominal" and call the nouns they relate to their "co-nouns"; conversely, we refer to the adjectives related to the nouns as their "co-adjectives". Table 1 illustrates A-N pairs of different morphological relation.

We propose to analyze co-adjectives as having essentially the same meaning as their co-nouns, except for two differences: (i) Co-adjectives do not refer, unlike their co-nouns; (ii) the components of the adjective meaning that correspond to the referential and possibly further arguments of the noun are not arguments. The first point accounts for the fact that adjectives and first compound components are not syntactically accessible to determination; for that reason they are also not eligible to direct anaphora. The second observation explains why these adjectives and compound components are not subject to syntactic binding. We will therefore assume the following relationship between, for example, the noun mother and its co-adjective maternal. The meaning of mother can be represented as in (7a), with the referential argument variable marked by underlining. The meaning of the co-adjective maternal would be the same, but with free variables instead of lambda-bound ones, and no variable with referential status (7b).

$$
\begin{aligned}
& \text { a. } \quad \text { mother }=\lambda \underline{x} \lambda y \cdot \operatorname{mother}(\underline{x}, y) \\
& \text { b. } \quad \text { maternal }=\operatorname{mother}(x, y)
\end{aligned}
$$


Thus, the semantic relationship between co-nominal adjectives and their co-nouns is essentially one of identity, while the difference in terms of arguments to be bound and treated as referential is due to the difference in grammatical category. Co-adjectives, one could say, are nouns in the guise of an adjective, or nouns functioning like an adjective.

While the notion of co-nominal A highlights its relation to a semantically closely related noun, we also want a new term for these adjectives when they combine with a noun. The term 'relational' adjectives has rightly been criticized as sub-felicitous (see Morzycki (2016: p.49)). It also is used in a way so as to cover adjectives of different semantic classes such as fake in fake gun, occasional in occasional smuggler, alleged in alleged thief, beautiful in beautiful dancer, and truly relational ones like municipal in municipal kindergarten, each plausibly requiring a different compositional analysis. We therefore introduce a new term for adjectives that are used to express a relation between two things: linking adjective (LA). This adjective class will include all co-nominal adjectives. What we called role-denoting relational adjectives above are a special case of co-nominal LAs with a role-denoting co-noun.

The paper is organized as follows: In section 2 we briefly discuss the kind-based analysis of relational nouns in McNally and Boleda (2004) and the later analysis in Arsenijevic, Boleda, Gehrke, and McNally (2014). We criticize these analyses for their use of kinds and for not capturing the wide range of possible relations involved with relational (i.e. linking adjectives). In section 3 we develop the ontological assumptions underlying our analysis, including a discussion of frame semantics, the representational framework we use, in section 3.4. Finally, sections 4 and 5 are devoted to our analysis of role-related adjectives.

\section{Existing accounts of relational adjectives}

\subsection{McNally and Boleda (2004)}

McNally and Boleda (2004) argue that relational adjectives denote properties of kinds, in the sense of Carlson (1977), and not properties of ordinary individuals (as adjectives like happy or green are). McNally and Boleda (2004) build an account of RAs that takes inspiration from Larson's 1998 analysis of non-intersective event-related modifiers like beautiful.

An observation with beautiful, going back at least to Siegel (1976), is that beautiful can have more than one pattern of modification: an intersective pattern where the adjective attributes a property to an individual, and a subsective pattern where the adjective attributes a property to an individual-event pair. Larson (1998) argues that adjectives like beautiful are always intersective, but can be predicates of different arguments when they are available. Abstracting away from the connective between the restriction of quantifier $Q$ and its scope, in (8a), the modifier beautiful predicates of the individual who is a dancer (the individual olga), while in (8b), beautiful predicates of the event of dancing that the dancer participates in (event $e$ ).

$$
\begin{aligned}
& \text { a. } \quad \llbracket \text { Olga is a beautiful dancer } \rrbracket=Q e[\text { dance }(e, \text { olga }) \ldots \text { beautiful }(\text { olga })] \\
& \text { b. } \quad \llbracket \text { Olga is a beautiful dancer } \rrbracket=Q e[\text { dance }(e, \text { olga }) \ldots \text { beautiful }(e)]
\end{aligned}
$$


McNally and Boleda (2004) adopt this strategy of predicating non-intersective adjectives on other parameters. Following Carlson (1977), they assume that kinds are a basic sort, a basic sort of (abstract individuals), but unlike Carlson, they further assume that common nouns have a slot in their argument structure for a kind as well as a non-kind individual, making the denotations of common nouns relations between kinds and individuals. ${ }^{3}$ The semantics for a common noun such as architect would thus look essentially like (9), where $R$ is a relation that holds between a kind and an individual just in case that individual is a member of that kind.

$$
\llbracket \operatorname{architect} \rrbracket=\lambda x_{k} \lambda y_{o} . R\left(x_{k}, y_{o}\right) \wedge \operatorname{architect}(x)
$$

Having assumed kinds in their ontology, they proceed to suggest that certain adjectives denote properties of kinds rather than of individuals. The adjective technical (e.g., technical architect) is analyzed as denoting a property of kinds, as shown in (10).

$$
\llbracket \text { technical } \rrbracket=\lambda x_{k} \cdot \operatorname{technical}\left(x_{k}\right)
$$

Lastly, they make the Larsonian move of saying that adjectives predicating of kinds can predicate of the kind argument of common nouns, just as adjectives predicating of events may predicate in certain circumstances of the event argument of some nouns.

$$
\llbracket \text { technical architect } \rrbracket=\lambda y_{o} \exists x_{k} \cdot R\left(x_{k}, y_{o}\right) \wedge \operatorname{architect}\left(x_{k}\right) \wedge \operatorname{technical}\left(x_{k}\right)
$$

Criticism We object to the use of kinds in this way. Carlson introduces kinds as referents of generic indefinites or of species terms like $\mathrm{dog}$. Ordinary common nouns in non-generic use, however, denote just a class, or type — of objects, not of kinds. It does not make much sense to assume that there are certain kinds that are architects, which is not the same as to assume that there are different kinds, i.e. subclasses, of architects. Even more questionable is the assumption that the adjective technical, along with a much more comprehensive crowd of other non-intersective adjectives, predicates about kinds. In our view, there is no property common to technical architects, technical problems, technical colleges, or technical instructions, except that they relate in some way or other to techniques. Not only do these things-be they kinds or just objects-have nothing in common if they are characterized as "technical" such things, they are even of ontological kinds so different that they can arguably be considered to not share any properties at all. ${ }^{4}$ Rather than assuming that LAs denote properties of kinds, we propose that these adjectives do not predicate at all. This accounts for the fact that they cannot be freely used predicatively. ${ }^{5}$ Analyzed like maternal in (7b), they do not have an argument to saturate.

We accept the attempt to "marry" $\mathrm{A}$ and $\mathrm{N}$ before they are applied to an object-type referent of the whole combination. For co-nominal As, this is essentially a marriage between two N concepts. There is no higher type involved than predication about objects, but the marriage is between concepts, not individuals (for example, a marriage of two type $\langle e, t\rangle$ concepts). In a conceptual approach to semantics, the concepts associated with nouns define a kind, or class, or

\footnotetext{
3 Type $k$ for kinds, and type $o$ for individuals (objects).

${ }^{4}$ See Löbner (2017) on an ontology of objects in terms of possible attributes. The proposed formal approach to global frame-ontologies provides criteria for deciding if two individual objects can have properties in common.

${ }^{5}$ On apparent counterexamples see the remarks in 2.2 .
} 
type, of objects by describing a single case. The meaning of architect describes an object of the type we call architects. The concept technical defines the abstract type of the adjective's co-noun technique $(s){ }^{6}$ These two concepts are married so as to form one coherent concept that includes both; let us notate this concept as technique $\bullet-$ architect. They must be linked in a way that technique(s) figure in the architect concept as we understand the notion of technical architect. $\mathrm{N} 1 \stackrel{\mathrm{N} 2}{ }$ is a cover notation that does not stand for any particular way of linking two noun concepts. As we adopt frame format concept representations (or equivalently AVMs), the connection between the two concepts/frames will be implemented by unification. ${ }^{7}$

To summarize, we do not adopt a kind-based analysis. Rather, we propose to model the 'marriage' between a LA and an $\mathrm{N}$ as an operation which unifies the meanings of the two expressions.

\subsection{Expansion of the kind-based approach to ethnic adjectives}

Arsenijevic, Boleda, Gehrke, and McNally (2014) build on the analysis in McNally and Boleda (2004) in analyzing ethnic adjectives (EAs), adjectives such as French and Canadian. They argue that these adjectives always classify a nominal according to some physical location, such as a nation. Some examples are given in (12), where in these cases the modified nominal is said to have some relation to the nation the EA relates to.

a. French wine

b. French agreement (to participate in the negotiations)

The suggestion by Arsenijevic et al. is that the adjective encodes a thematic relation between a kind and a country, what they call Origin. This relation holds of kinds and countries only if the kind comes into existence within the spatial domain of the country:

$$
\operatorname{Origin}(x, y) \text { iff } x \text { comes into existence within the spatial domain of } y
$$

EAs, like RAs, target the kind argument of the common noun they modify, making them intersective at the kind level. Crucially, the adjective, due to Origin, provides further constraints on this intersection. This is illustrated in (14).

$$
\llbracket \text { French wine } \rrbracket=\lambda y_{o} \exists x_{k}\left[R\left(x_{k}, y_{o}\right) \wedge \text { wine }\left(x_{k}\right) \wedge \operatorname{Origin}\left(x_{k}, \text { France }\right)\right]
$$

Both of these analyses model the non-intersectivity of RAs and EAs by predicating the adjective on a parameter other than the individual argument, with the analysis from Arsenijevic et al. (2014) adding an layer of complexity by explicitly naming the relation that obtains between a kind and the country named by the adjective. However, we think that this analysis is not adequate for ethnic adjectives, and also cannot be transferred to role adjectives.

\footnotetext{
${ }^{6}$ Actually, this example is not easy to handle, as it is not quite clear what the co-noun of technical could be assumed to be if it is to account for all the widely varying semantic contributions the A can effect.

7 See Löbner (2013: chapter 12) for the outlines of an account for analyzing N-N compounds along these lines.
} 
Criticism We share the idea that there is some relation that links the referent of the A's co-noun to the noun the A combines with. However, it appears obvious to us that: $(i)$ the linking relation, for LA's whose co-noun denotes a country, is not always Origin; (ii) the linking relation is not unilaterally contributed by the LA; and (iii) the linking relation applies at the level of objects, for example, between the country and the objects the noun denotes.

As to the first objection, consider the following examples (from the BNC online corpus):

Canadian government, $C$. prime minister, $C$. immigrants (= immigrants to Canada), $C$. territory, C. citizenship, C. army, C. history, C. Rockies, C. border, C. dollar, C. reunion, C. geography, C. economics, C. policy, C. law, C. writer

None of these can be paraphrased as ' $[\mathrm{N}]$ with origin in the region of Canada.' Rather, in each case, a different relation obtains between Canada and the referent of the noun. Obviously, the second noun itself participates in selecting the relation. Among the nouns in (15), government, prime minister, territory, citizenship, army, and policy are relational nouns and Canadian specifies their relational argument as Canada, the state. Similarly, geography and border are relational nouns with a region or country as an argument, here specified as Canada, the region (note that Canada, the state, is ontologically not the same as Canada, the region). In these cases, the relation is not contributed by the RA, and it is not Origin. Rather, the relation is defined in the lexical meaning of $\mathrm{N}$, which specifies the relation between the referential argument and the relational argument. ${ }^{8}$ This should not be taken to suggest that the linking relation is always contributed by the nominal concept; obviously, LAs combine with all types of nouns, including sortal nouns, which lack relational attributes. ${ }^{9}$ Among the examples in (15), writer is a sortal noun. A Canadian writer may be a writer born in Canada, or a writer living in Canada, or a writer participating in the Canadian literary scene; in any event we may assume a bridging relation like ' $x$ was born in $y$,' ' $x$ lives in $y$ ', or ' $x$ participates in the literary scene of $y$ ' that takes Canada and the writer as the $y$ and the $x$ arguments, respectively. Thus the possible relations come from both the LA and the N, and how the different sorts of thing they denote can be connected.

Linking adjectives may have 'sisters,' adjectives of the same form that are lexicalized as ordinary intersective property adjectives (PAs). Canadian is certainly among them; there is a lexicalized sense variant that means basically 'from Canada.' The origin of this adjective can be considered to be due to a lexicalization of the LA with a particular linking to the country noun. Thus, there are two adjectives: the co-nominal LA Canadian and a property adjective Canadian ${ }^{10}$ that implements a particular, frequent linkage of the LA; there is also the noun Canadian in the sense 'native or inhabitant of Canada.' There is nothing "inelegant" (Arsenijevic et al., 2014) in recognizing polysemy. In other cases of what appears to constitute predicative use of LAs, we assume that the LA is coerced into a PA by adding an argument and a relation to the co-noun content. For instance, there are predicative uses of the LA public like in (16):

\footnotetext{
${ }^{8}$ See Löbner (2013: p. 69) on the possessum-possessor relation inherent to the meanings of relational nouns.

${ }^{9}$ See Löbner (2011) on types of nouns, including sortal and relational.

${ }^{10}$ Morzycki (2016: p. 14ff), apparently relating to the PA variant, uses Canadian as a paradigm case of an intersective adjective.
} 
(16) The university is public, while nourished by the strong support of its alumni. ${ }^{11}$

These uses seem to be acceptable only if there is support by using the LA frequently with a particular linkage supported by the argument noun of the predicative construction. The observation remains that this mechanism of coercion cannot be applied to the majority of LA-N combinations possible. ${ }^{12}$

\subsection{Applying the findings to presidential}

The objections raised against the use of kinds in analyzing relational adjectives and assuming a particular relation encoded in the adjective carry over immediately to combinations of presidential with a noun. Here, too, we encounter a wealth of relations between the president and the noun referent, as shown in Table 2.

\begin{tabular}{|c|c|}
\hline presidential $N$ & Relation \\
\hline presidential election & election to determine the next president \\
\hline presidential office & the office of president \\
\hline presidential office & office for official action by the president \\
\hline presidential advisor & advisor to the president for official action \\
\hline presidential visit & visit by the president as the president \\
\hline presidential visit & visit to the president as the president \\
\hline presidential motorcade & motorcade [for] escorting the president \\
\hline
\end{tabular}

Table 2: Relations encoded by presidential $N$

\section{Ontological background}

\subsection{Social ontology}

Our analysis will depend to a large degree on the ontology we assume in order to be able to talk about things like roles, offices, and official action. Following Searle (1995) we assume a layered ontology, with a higher-level social ontology carried by a lower-level physical ontology of "brute facts". A human being is an entity in the lower ontology, while when considered a person they constitute a social being, a potential actor in society. The crucial relation that links the social world to the underlying physical world is the relation " $X$ counts as $Y$ in context $C$ " Searle (1995: p. 28). Nodding one's head is a physical action that may count as the social action of approval; a piece of metal or paper may count as money, a person may count as the president of a state-all under appropriate circumstances which are ruled, for example, by convention or law. We assume that the social ontology is in itself multi-layered; the count-as relation may hold between entities of different levels within the social ontology (for example, when the person Angela Merkel

\footnotetext{
$\overline{11}$ http://www.ccam-va.com/university-members/

${ }^{12}$ Examples like this add to the argument against considering this co-nominal adjectives as predicating over kinds: this example involves reference to ordinary objects.
} 
counts as the chancellor of Germany). The discussion of the presidential examples will relate to distinctions within the social ontology.

\subsection{Office and person levels of action}

We distinguish in the ontology between two different sorts of acts: acts that occur at the level of a person, and acts that occur at an official level. Social offices are defined (in large part) by the rights, duties and official acts involved with the social role. Depending on the institutional norms and laws, presidents (for instance) might be empowered to wage war, negotiate treaties, sign bills into law, and so on. These are abilities that are reserved for the officeholder in the context of their official role. However, being abstract institutions, offices themselves cannot execute acts; they have no way to directly enact the physical doings that will count as the respective social types of action. Official acts must be implemented by concrete persons (and ultimately by the physical human beings who, for instance, move their hand when signing a bill).

\subsection{Connections between levels}

We introduce three relations that mediate between ontological levels. The first is the function INC "incumbent." INC, when applied to an office, returns the person who is the incumbent at the given index. The second is the function IMPL "implementation." IMPL applies to official-level acts and returns the person-level act that implements it. The third is a relation C-CONST "constitution under circumstance." The inverse of IMPL, it relates a lower-level act to the higher-level acts it constitutes or counts as. C-CONST is not a function; the relation is transitive, and it also cannot be excluded that one act c-constitutes two different types of acts in parallel.

The C-CONST relation is an application of the notion of "level-generation" from Goldman (1970). Goldman, in developing his theory of action, argues that pairs of acts can be in an asymmetric relation with each other, such that one act is dependent on the other to generate it. Different acts in a generation, or C-CONST relations, correspond to different ways of assigning a given doing simultaneously to different types of action, at different levels in our ontology. For example, if the president, as an official action, signs a bill into law, this act is at the same time an act of moving their hand holding a pen, writing their name, signing a document, and investing its content with legal force. The actor of all this can do the first three acts as a private person (in different contexts), but the last one only in office. ${ }^{13}$ The official act is generated by the more basic acts. Crucially, acts level-generating or implementing each other must have the same agent (modulo the agent's level-role) and the same temporal extension.

As a final step, we suppose that the usual thematic roles (AGENT, THEME and so on) are defined as functions over both official-level and personal-level acts, returning individuals who fill those roles in those events. The overall picture we get for our ontology is diagrammed in Figure 1.

\footnotetext{
13 The notion of c-constitution is more general than Searle's counts-as relation. The difference does not matter in this paper; see Goldman (1970: Ch. 2) for the broader notion.
} 


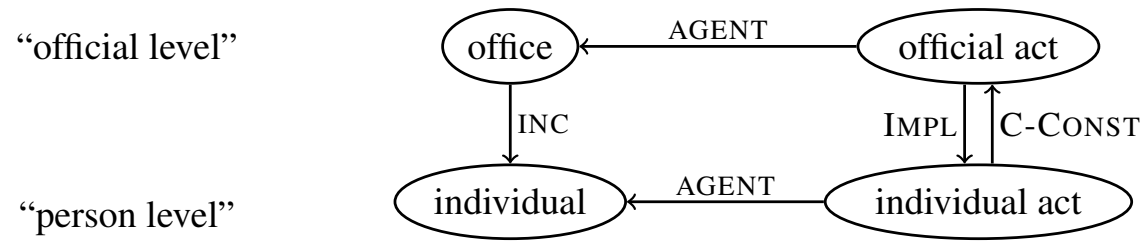

Figure 1: Diagram of a social ontology

\subsection{Frames}

Our analysis is developed using Frame Semantics (Petersen, 2007; Löbner, 2014, 2017), a theory regarding the structure of concepts based on the notion of frames in Barsalou (1992). Frames encapsulate lexical knowledge, world knowledge, or contextual knowledge in a single, unified format of representation. Thus, the frame theory we adopt is able to capture fine-grained semantic distinctions and not only features related to argument structure. A frame is a recursive attribute-value structure. An attribute is a function to capture a property, by assigning an individual entity in the underlying ontology a value for that attribute. For instance, an attribute COLOR would assign a color value to a visible object, PRICE a price to an economical good, BORDERS the borders to a region, or HEAD [OF STATE] the head of a state. Attributes have exactly one value for a given entity; they are functions, but the value may be described by a whole frame. This is what makes frames recursive structures. In a frame, one element is distinguished as representing the individual the whole frame describes.

Different styles for representing frames have emerged, such as the use of attribute-value matrices (AVMs), frame diagrams, and first-order logic. These representations are equivalent; frame diagrams can be transformed into AVMs or first-order predicate logical representation without loss of generality. ${ }^{14}$ We use a combination of frame diagrams and logical representations. For frame diagrams, nodes are represented with ovals or other graphic forms, with a double border for the central node, which represents the individual the whole frame describes. When relevant, nodes carry indices; they correspond to individual variables in the logical formulae. Nodes may also carry type labels; sometimes we will write the type-labels into the nodes. Arrows connecting nodes represent attributes, with the arrow pointing towards the value. Attribute arrows are always labeled. Composition of frames is modeled as unification (Carpenter 1992).

The use of frames in the chosen approach also involves ontological assumptions; the frame theory adopted is based on the assumption of an underlying global frame ontology which defines which attributes are available and admissible and which sorts and types of individuals are in the frame universe (Löbner, 2017: $\S 2$ ). The assumptions concerning social ontology are considered to be integrated in the frame-ontology. The functions INC and IMPL can be used as attributes for social-level offices (with a person incumbent) and social acts, respectively.

\footnotetext{
14 See Löbner (2017) for a general discussion.
} 


\section{Presidency, president, presidential, and presidency}

\subsection{The preside frame}

As mentioned previously, we propose that the same concept is present in both president and presidential. The only differences concern the status of the frame elements. The preside frame (and thus the meaning of president and presidential) is based on the notion of an event of some person being the president of some organization. Crucially, this type of event is defined at a social level above the simple person level. We introduce the metalanguage predicate preside for the event of a presidency. For events of this type, there are three attributes (equatable to thematic roles) that are presently relevant. The first is ORG (for "organization"); it has as its value the organization that is presided over or headed. The second attribute is HEAD, which returns the one who heads the organization, roughly the agent of the presiding event. Finally, $\tau$ represents the temporal extension of the event. Figure 2 demonstrates the preside frame.

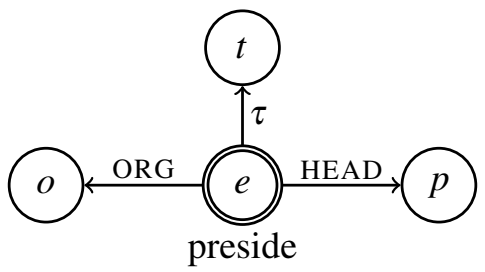

Figure 2: The preside frame

Our position is that certain role-denoting nominals such as president have an event in their lexical semantics that encompasses the official acts pertaining to that role. However, although we believe there is an eventive predicate in the lexical semantics of role nouns, this isn't a commitment to role nouns being derived in any sense from verbs or there being a co-verb to the noun. What matters is the lexical semantics of the nouns themselves. ${ }^{15}$ Additional evidence is provided by the fact that role nouns can combine with adjectives like frequent and constant. This type of adjective has been argued to be licensed by event structure (Grimshaw, 1990). It's possible to find attestations for constant and frequent modifying role nouns:

$$
\text { I was a constant president of our class in my elementary [school] years... }{ }^{16}
$$

Another character whose life intertwines with the protagonists throughout the novel was Carter Harrison, a frequent mayor of Chicago. ${ }^{17}$

\footnotetext{
15 That certain nouns can be supposed to have an event argument even if not morphologically derived from a verb was independently made in Larson (1998); he gives examples like daily newspaper, just king, stray bullet, and fast horse. See also Vendler (1967) for a predecessor of this proposal.

16 http://www.onlinejobs.ph/jobseekers/info/67905

17 http://www.storycirclebookreviews.org/reviews/gildedcage.shtml
} 


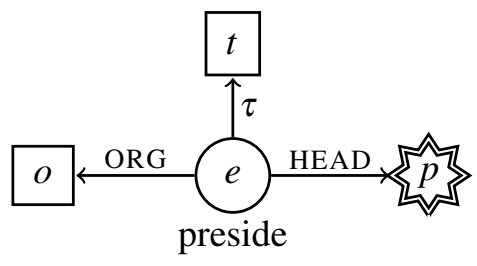

Figure 3: president ('office')

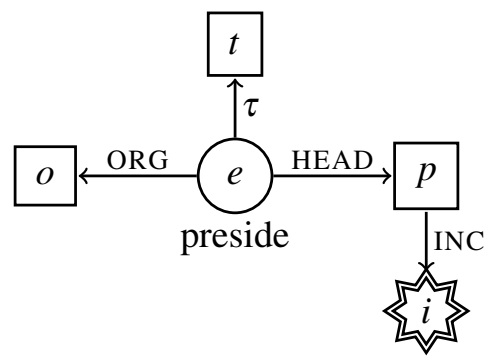

Figure 4: president ('person')

\subsection{President}

We observe that the noun president can be used to refer to individuals at either the official level or the person-level of the ontology we have constructed-in other words, to refer to a role-individual or to the person inhabiting the role. The examples in (19a) and (19b) illustrate this, where (19a) has president referring at the official level, and (19b) at the person level.

a. The president visited Canada as part of an official trip.

b. \#The president visited his mother as part of an official trip.

The frame in Figure 3 (represented using predicate logic in (20)) represents the core of the meaning of the noun president. Many attributes would have to be added to the value node of the HEAD attribute for an adequate description of a president. The frame is essentially the frame for preside, except that the grammatical status of the nodes is specified and the central node is shifted to the president node $p$. This shift is what makes the frame represent the president (in the 'office' sense) rather than an event of 'presiding.'

$$
\text { president }_{o f f i c e}=\lambda o \lambda t \lambda p[p=\operatorname{HEAD}(\imath e \cdot \operatorname{preside}(e) \wedge \tau(e)=t \wedge \mathrm{ORG}(e)=o)]
$$

In lexical frames, we mark elements to be bound as arguments in syntax with rectangular boxes; in the corresponding predicate logic formula, their indices (essentially variables) receive lambda-binding. Referential nodes are surrounded by a star. The central node is marked by a double border. In Figure 3, the central node is the one for the president (in the 'office' sense) indexed with $p$, a referential node; the node $o$ is an argument node representing the relational argument of president (the organization). The node $t$ represents the time argument; for the sake of simplicity, president $_{\text {office }}$ is only defined for time periods of a full presidency. We supply the variable $e$ with an iota operator since we consider it adequate to assume that there can be only one "presiding" event at a given time for a given organization.

The concept for president in the 'person' reading is derived from the frame in Figure 4 (represented using predicate logic in (21)) by adding the attribute INC to node $p$ and shifting the central and referential node to its value node $i$. This extension comes for free as this attribute is defined for all office-entities provided the office is not vacant.

$$
\text { president }_{\text {person }}=\lambda o \lambda t \lambda i[i=\mathrm{INC}(\operatorname{HEAD}(l e \cdot \operatorname{preside}(e) \wedge \tau(e)=t \wedge \mathrm{ORG}(e)=o))]
$$




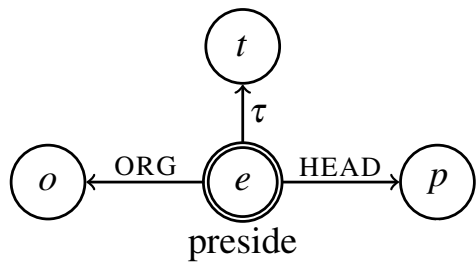

Figure 5: presidential

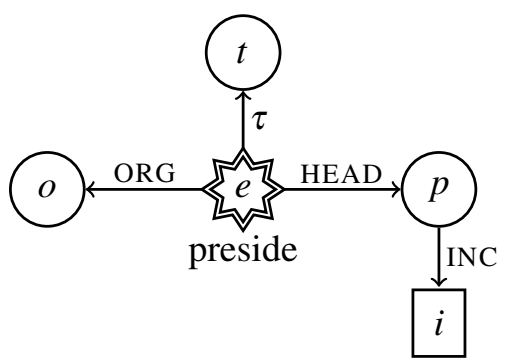

Figure 6: presidency

\subsection{Presidential}

The frame for presidential is essentially the same frame as for president $_{\text {office }}$, its co-noun. The presidential frame is represented in Figure 5. This frame has no referential node, as it fits an adjective (and not noun) frame. It also has no argument nodes either, as presidentially cannot have its temporal or relational arguments syntactically specified. This feature implements the property of LA that they do not predicate.

\subsection{Presidency}

We use the same basic frame to model the meaning of presidency. This is a relational noun referring to the event of a presidency for an incumbent possessor argument. The result is depicted in Figure 6. The four frames developed for president $_{\text {office }}$, president ${ }_{\text {person }}$, presidential, and presidency represent four variants of the same conceptual structure. Defining the central element invests the structure with a perspective concerning what element it is primarily related to. Investing certain elements with argument status concerns the way in which the structure is to be linked within the proposition frame for the whole sentence, while referential status amounts to a particular role the element plays when the proposition frame is related to the world.

\section{Compositional analysis}

\subsection{Predication at a level}

Some modifiers seem to be able to distinguish between official and personal senses, further supporting our claim that these levels are distinguished ontologically. As president is able to force a predication to be interpreted as official-level, while privately or as a private citizen forces a predication to be interpreted as personal-level. Both modifiers are acceptable if the sentence can be interpreted as either official-level or personal-level.

(22) a. As president/\#Privately, the president vetoed the bill.

b. Privately/\#As president, the president combed their hair.

c. As president/Privately, the president visited Canada. 
(23) The King, visiting as a private citizen, was reticent about his political ambitions, saying only that he wanted to help Romania. (BNC HLJ 2180)

We suppose that action at a level (e.g., action at the official-level or personal-level) requires event participants at that same level of the ontology. An event at the official-level, for instance, will require that both Agent and Theme of that event are also construed as being official-level entities. But then what are we to make of cases where entities seem to be mismatched in levels?

\subsection{The official level and elaboration}

When a DP with a role noun is the subject of the verb visit, it is possible to interpret the Theme as an individual at the official level of the social ontology (rather than the personal level). When the DP corresponding to the Theme inherently denotes at the official level, it's quite clear what the Theme attribute of the visiting event should have as its value. However, a difficulty arises when the DP doesn't inherently denote at the official level (e.g., that there is a mismatch of levels). For an illustration of this, consider (24). The name Trudeau naturally denotes the personal-level individual Justin Trudeau, but the sentence is most naturally interpreted as being an official visit between two heads of state (official-level individuals).

How is it that Trudeau comes to denote the head-of-state-Trudeau rather than the private-citizenTrudeau? Our solution is that the semantics of a term can be elaborated using a combination of world knowledge and the IMPL and INC mappings between levels. The example is fleshed out here in prose; the resulting frame is represented in Figure 7.

First, the Agent of the visiting: as the sentence asserts about an official-level visiting event, the Agent role of 'visit ${ }_{o}$ ' must unify with an official-level agent. The value $p$ of the HEAD attribute of the preside frame, the president, is suitable here. However, an official level Theme is also required. But, the name Trudeau denotes an entity at the personal level, not the official level. In order to have a Theme at the appropriate level, world knowledge and contextual knowledge is used to infer an individual at the official-level, such that the personal-level individual 'Trudeau' stands in an incumbency relation (via INC) with that individual (e.g., Justin Trudeau in the role of head of state). This is illustrated in the rightmost part of Figure 7. Finally, an official-level visit must be appropriately implemented by personal-level action (see section 3); we therefore need to project down from the 'visit ${ }_{o}$ ' node to a corresponding personal-level action node 'visit $p$ '. The Theme argument at this level is the personal-level 'Trudeau.' Note that 'visit $p$ ' does not simply stand for a visit at the personal level. Being the implementation of an official visit, it stands for what the office incumbents do when one is paying an official visit to the other: they stage an official visit rather than visiting as private persons. 


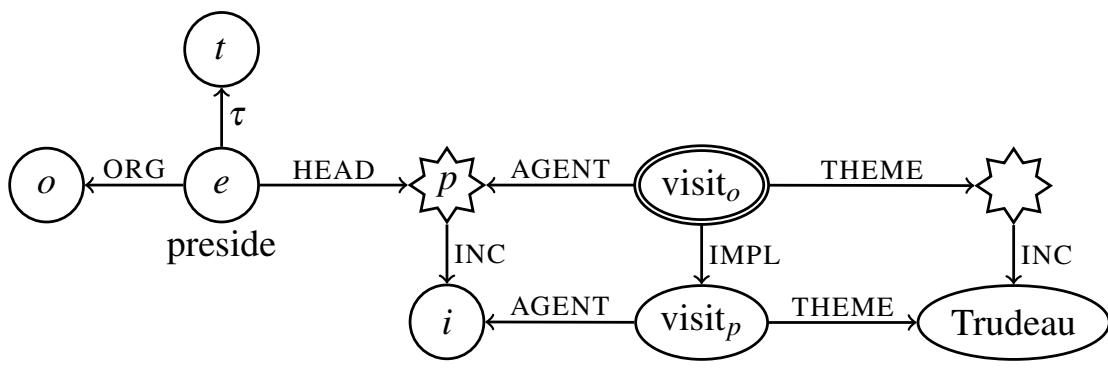

Figure 7: Frame for (24) ('official' level reading)

\subsection{The personal level}

Predications with president can also be situated at the personal level of the ontology, giving us a reading where something not necessarily official has occurred. For instance, if the internal argument of visit denotes an individual who does not have a (relevant) official-level role available for them, then the predication will be interpreted as applying at the personal level. An example of this is as in (25), where, because mothers do not normally have a relevant official role, the sentence is interpreted as it being a personal and not official visit. Of course, persons who are the incumbents of offices can also be visited as private citizens as well.

a. The president visited his mother.

(personal)

b. (As a private citizen,) the president visited Trudeau.

(personal)

In contrast to the analysis in the previous section, no elaboration of the official-level is necessary for visit in this case; the reason, to put it simply, is that an official-level visit did not occur. Predication at the personal-level can occur with president using INC to map from the office of the president to the incumbent. The frame in Figure 8 shows this.

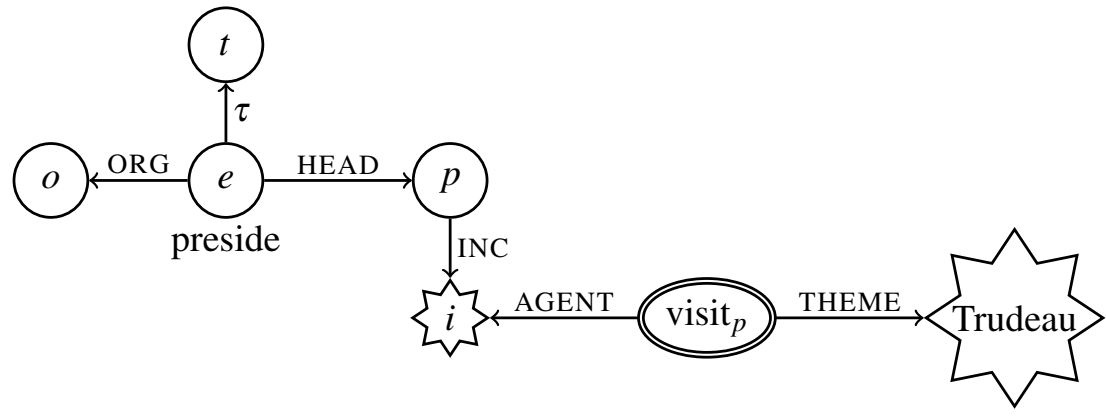

Figure 8: Frame for (25b) ('personal' level reading)

\subsection{Unification and presidential visit}

Recall that the relational adjective presidential requires an official-level reading: for example, presidential visit only allows for an interpretation where the visit is part of the official sphere of duties related to the president. We model this by supposing that the concept for presidential only provides nodes at the official level—that is, no nodes related to the personal level of visit, such 
as the incumbent, are provided by presidential. The consequence of this move is that unification of the visit concept with the concept for president can only happen at the official-level of our social ontology. While the DP the president provides for the possibility of reference at multiple levels, presidential only provides for reference at the official level. This means that presidential cannot be ambiguous with regard to which level is selected for predication.

This does not rule out other sources of ambiguity, however. One source of potential ambiguity is the event nominal visit itself. The concept for visit encodes (at least) two thematic roles, that of an Agent (the one doing the visiting) and that of a Theme (the one being visited). If neither role is saturated, with either syntactically explicit or contextually implicit arguments, we should expect presidential visit to be ambiguous, due to the possibility of the official-level president node being able to unify with either the Agent or the Theme thematic role. These possibilities are illustrated in (26) and (27). To explicate a bit, (26) shows the result of unifying the Agent node of the visit frame with the president (HEAD) node.

$$
\text { presidential visit }=\lambda e \exists x\left[\begin{array}{c}
\operatorname{visit}(e) \wedge \operatorname{THEME}(e)=x \wedge \\
\operatorname{AGENT}(e)=\operatorname{HEAD}\left(l e^{\prime} \cdot \operatorname{preside}\left(e^{\prime}\right)\right)
\end{array}\right]
$$

Example (28) shows the result of unifying the Theme node of the visit frame with president.

$$
\text { presidential visit }=\lambda e \exists x\left[\begin{array}{c}
\operatorname{visit}(e) \wedge \operatorname{AGENT}(e)=x \wedge \\
\operatorname{THEmE}(e)=\operatorname{HEAD}\left(l e^{\prime} \cdot \operatorname{preside}\left(e^{\prime}\right)\right)
\end{array}\right]
$$

These multiple possibilities for unification predict that an ambiguity should manifest itself in examples like presidential visit, where the semantic representations include both an individualdenoting node and multiple thematic arguments. This seems to be borne out; corpus and search engine findings show speakers do seem to use presidential visit in a way that would be consistent with the analysis above, where the president can be the Agent (visitor) or Theme (visitee) of a visit. While uses of the Agent-related variant are abundant, (28) provides an attestation of the Theme-related use. ${ }^{18}$ Other role-denoting LAs also have non-Agent uses, such as in (29), where papal meeting can mean a meeting with the pope rather than by the pope.

(28) Will NBA champions continue to visit the White House under Donald Trump? One of the first players to make the presidential visit gives his opinion. ${ }^{19}$

$$
\text { Abuse survivor disputes removal from Vatican commission, seeks papal meeting. }{ }^{20}
$$

Some accounts of RAs, such as Alexiadou and Stavrou (2011), treat them as essentially nominals, and argue that classificatory RAs syntactically saturate an external argument position. But, patterns such as those exemplified above are difficult to account for in those types of accounts, as the RA would need to be able to saturate both internal and external arguments (as the Theme

\footnotetext{
${ }^{18}$ For readers unacquainted with the tradition, members of the winning team of the NBA finals championship game typically visit the White House and meet with the American president.

19 http://www.golf.com/nba/2017/01/20/nba-white-house-visit-satch-sanders-celtics-jfk-donald-trump

20 http://www.ncronline.org/news/accountability/abuse-survivor-disputes-removal-vatican-commission-seekspapal-meeting
} 
argument is presumably an internal argument). In our analysis, the ability of RAs to be linked to either a Theme or an Agent role is a natural consequence of the machinery we use to analyze RAs. In this regard, we follow Arsenijevic et al. (2014), who also argue that the apparent argument-saturating behavior of RAs is only apparent and can be derived from the semantics of the construction (although our account does differ from theirs in crucial ways).

\section{Conclusion}

To conclude, we argue that the analysis of at least certain types of relational adjectives-our role-denoting relational adjectives or presidential-type adjectives-requires a richer semantic ontology than normally supposed. We develop an ontology that includes a social aspect to it, modeling a distinction between personal and social acts. Using this ontology we distinguish between levels of action that constitute or implement each other; our crucial example we develop is personal acts of visiting as implementations of official visitations. Roles are thus derived from the thematic roles available with events at different levels of the ontology.

The frame-based analysis we proposed differs from traditional approaches in formal semantics in a few relevant respects. First, frame representations allow for the type of decompositional strategy we pursued in our analysis, of mixing lexical, contextual, and world knowledge in a single representation. As the readings with president and presidential are driven in large part by context, modeling these different sources of knowledge in one place made stating their interaction relatively simple. Second, the use of unification as the basic mechanism of composition for frames allowed for a succinct way of capturing different meanings for presidential visit (e.g., a visit to or by a president), due to multiple possibilities for unification. And in a certain sense, our analysis is "intersective." Unification of frames adds conditions to the single frames that are involved. In particular, unifying the noun frame with the LA frame adds conditions to be fulfilled by the referent of the noun. "Intersecting" the two frames in this way is more subtle and involved than plainly conjoining the two concepts.

Finally, this is a project very much in the spirit of "natural language metaphysics" as understood by Bach (1986) and Moltmann (2017). Our analysis is founded on a rich ontology, an ontology that includes social individuals and acts, and distinguishes between acts that implement or constitute each other, in the sense following Goldman (1970). From this ontology, we derive the notion of a social role; social roles are simply thematic roles of events at the official-level of our ontology, and linked to concrete persons on the personal-level via an incumbency relation. Official-level acts are similarly linked to concrete personal-level acts via an implementation relation. These levels in the ontology point towards natural language being sensitive towards acts of different levels of abstractness.

\section{References}

Alexiadou, A. and M. Stavrou (2011). Ethnic adjectives as pseudo-adjectives: a case study on syntax-morphology interaction and the structure of DP. Studia Linguistica 65(2), 117-146. Arsenijevic, B., G. Boleda, B. Gehrke, and L. McNally (2014). Ethnic adjectives are proper adjectives. In Proceedings of CLS 46, pp. 17-30. 
Bach, E. (1986). Natural language metaphysics. In Logic, Methodology, and Philosophy of Science, pp. 573-595. North Holland.

Barsalou, L. (1992). Frames, concepts, and conceptual fields. In A. Lehrer and E. F. Kittay (Eds.), Frames, Fields, and Contrasts: New Essays in Semantic and Lexical Organization, pp. 21-74. Hillsdale, New Jersey: Lawrence Erlbaum Associates.

Carlson, G. (1977). Reference to Kinds in English. Ph. D. thesis, University of Massachusetts, Amherst.

Goldman, A. I. (1970). A Theory of Human Action. Princeton University Press.

Grimshaw, J. (1990). Argument Structure. MIT Press.

Larson, R. K. (1998). Events and modification in nominals. In D. Strolovitch and A. Lawson (Eds.), Proceedings of Semantics and Linguistic Theory, Volume 8, pp. 145-168.

Löbner, S. (2011). Concept types and determination. Journal of Semantics 28(3), 279-333.

Löbner, S. (2013). Understanding Semantics. Routledge.

Löbner, S. (2014). Evidence for frames from human language. In T. Gamerschlag, D. Gerland, R. Osswald, and W. Petersen (Eds.), Frames and Concept Types, pp. 23-67. Springer.

Löbner, S. (2017). Frame theory with first-order comparators: Modeling the lexical meaning of punctual verbs of change with frames. In H. H. Hansen, S. E. Murray, M. Sadrzadeh, and H. Zeevat (Eds.), Logic, Language, and Computation: 11th International Tbilisi Symposium on Logic, Language, and Computation, pp. 98-117. Springer.

McNally, L. and G. Boleda (2004). Relational adjectives as properties of kinds. In O. Bonami and P. Cabredo Hofherr (Eds.), Empirical Issues in Formal Syntax and Semantics 5, pp. 179-196.

Moltmann, F. (2017). Natural language ontology. In Oxford Research Encyclopedia of LInguistics. Oxford University Press.

Morzycki, M. (2016). Modification. Cambridge University Press.

Petersen, W. (2007). Representation of concepts as frames. The Baltic International Yearbook of Cognition, Logic and Communication 2, 151-170.

Searle, J. R. (1995). The Construction of Social Reality. Simon and Schuster.

Siegel, M. E. A. (1976). Capturing the Adjective. Ph. D. thesis, University of Massachusetts Amherst.

Vendler, Z. (1967). Linguistics in Philosophy. Ithaca, NY: Cornell University Press. 